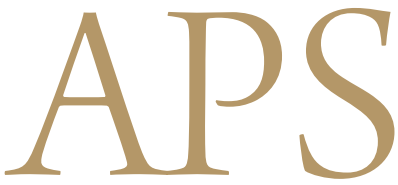

Archives of Plastic Surgery

\title{
Optimal Initial Dose of Chloral Hydrate in Management of Pediatric Facial Laceration
}

\author{
Su Han Koo, Dong Gwan Lee, Heakyeong Shin \\ Department of Plastic and Reconstructive Surgery, Dongguk University College of Medicine, Gyeongju, Korea
}

Background Chloral hydrate $(\mathrm{CH})$ is the primary agent most commonly used for pediatric sedation prior to diagnostic, therapeutic procedures. In the management of pediatric facial laceration, the initial dose of $\mathrm{CH}$ has to balance the need for adequate sedation against the need to minimize sedative complications.

Methods A retrospective review of medical records of 834 children who visited our emergency room for facial lacerations from August 2010 to September 2012 was conducted. They were divided into six groups on the basis of the initial dose of $\mathrm{CH}$ administered. Further, each group was compared with the standard group (70 to $\leq 80 \mathrm{mg} / \mathrm{kg}$ ) with respect to sedation success, augmentation dose, failed sedation, time to procedure, and time of stay.

Results With respect to the complication rate, only group 1 (range, 40 to $\leq 50 \mathrm{mg} / \mathrm{kg}$ ) showed a significantly lower complication rate. In the case of all the other variables considered, there were no significant differences among any of the groups.

Conclusions An initial $\mathrm{CH}$ dose of $48 \pm 2 \mathrm{mg} / \mathrm{kg}$ does not negatively affect the success rate of sedation or the need for additional sedative during the primary closure of facial lacerations in pediatric patients. Further, lower doses reduce the incidences of adverse effects and do not delay procedure readiness. Therefore, $48 \pm 2 \mathrm{mg} / \mathrm{kg}$ of CH can be considered the optimal initial dose for pediatric sedation.

Keywords Chloral hydrate / Conscious sedation / Infant / Child / Sutures
Correspondence: Heakyeong Shin

Department of Plastic and

Reconstructive Surgery,

Dongguk University College of

Medicine, 87 Dongdae-ro,

Gyeongju 780-350, Korea

Tel: +82-54-770-8242

Fax: +82-54-770-8501

E-mail: shinheakyeong@hanmail.net
No potential conflict of interest relevant to this article was reported.

\section{INTRODUCTION}

Chloral hydrate $(\mathrm{CH})$ is one of the most commonly used sedatives, and usually, $\mathrm{CH}$ is the primary agent used for pediatric sedation prior to diagnostic procedures, such as computed tomography, magnetic resonance imaging (MRI), echocardiography, and electroencephalography (EEG) [1]. In our plastic surgery department, $\mathrm{CH}$ is used for sedating children that need primary repair of facial lacerations in an emergency room. Unlike diagnostic procedures, primary repair is preceded by a painful pre-seda- tional injection of local anesthetics that may distress children before the induction of sedation. Furthermore, children may experience various mechanical stimuli during procedures. Although this higher level of stimulus might increase dose requirements, little information is available in the existing literature on the topic [2].

$\mathrm{CH}$ is a safe sedative with a low complication risk. Nevertheless, its potential adverse effects range from gastric distress, nausea, and vomiting that are mild and self-limited, to effects such as ataxia, lethargy, deep coma, respiratory depression, hypoten- 
sion, and cardiac arrhythmias that are potentially life threatening [3]. The average half-life of trichloroethanol, the first metabolite of $\mathrm{CH}$ and responsible for CH's pharmacological activity, is 8 hours (range, 7-9.5 hours) [4], and this long half-life may cause late re-sedation and other adverse effects after discharge. In the practical environment, despite the possibilities of re-sedation and other late adverse events, careful observation over the halflife of $\mathrm{CH}$ is unrealistic, particularly in the emergency room setting. Therefore, the initial dose should be as small as possible, as long as it is effective.

Thus, in view of the conflicting requirements of successful sedation for primary repair and the minimization of possible complications, guidance is required with respect to the optimal $\mathrm{CH}$ dose. In the existing literature and in pediatric textbooks, 50 to $100 \mathrm{mg} / \mathrm{kg}$ of $\mathrm{CH}$ is generally recommended, and $75 \mathrm{mg} / \mathrm{kg}$ is usually viewed as a standard dose in a number of publications [2,5-9]. Accordingly, we aimed to identify an optimal initial $\mathrm{CH}$ dose for pediatric sedation for primary repair by comparing the findings of patients who were given different $\mathrm{CH}$ doses.

\section{METHODS}

This study was conducted by retrospectively reviewing the medical records of 834 children who visited our emergency room for facial lacerations from August 2010 to September 2012. The sequence of procedures performed on the children was as follows: wound irrigation, injection of local anesthetics (lidocaine), administration of sedative, and wound suture in that order. These children were divided into six groups on the basis of the recorded initial dose range of $\mathrm{CH}$ administered in ascending order, as follows: group 1, 40 to $\leq 50 \mathrm{mg} / \mathrm{kg}$; group 2, 50 to $\leq 60 \mathrm{mg} / \mathrm{kg}$; group 3, 60 to $\leq 70 \mathrm{mg} / \mathrm{kg}$; group 4, 70 to $\leq 80 \mathrm{mg} / \mathrm{kg}$; group 5,80 to $\leq 90 \mathrm{mg} / \mathrm{kg}$; and group 6, 90 to $\leq 100 \mathrm{mg} / \mathrm{kg}$. Group 4 , which included the standard dose $(75 \mathrm{mg} / \mathrm{kg})$, was regarded as the standard group and was compared with the other groups with respect to sedation success, augmentation dose, failed seda- tion, time to procedure, and time of stay.

Categorical data, such as the incidence of adverse events and sedation failure, were analyzed using Fisher's exact and chi-squared tests as appropriate. Continuous data, such as age, weight, medication dosage, time to procedure, and time of stay, were analyzed using one-way analysis of variance with Dunnett's multiple comparisons test. P-values of $<0.05$ were considered significant.

\section{Definition of terms used in this study}

The following definitions were considered: 1) Sedation failure: sedation deemed inadequate after the administration of initial or of an augmentation dose of $\mathrm{CH}$, finally resulting in the inability to perform primary repair without physical restraint. 2) Sedation success: sedation conducted uneventfully without sedation failure during the procedure. Transient awakening or irritability followed by successful re-sedation was also viewed as sedation success. 3) Augmentation dose: the additional administration of $\mathrm{CH}$ due to inadequate sedation after initial administration. 4) Time to procedure: the time in minutes from the administration of $\mathrm{CH}$ to the documented time of a procedure. 5) Time of stay: the time in minutes from the administration of $\mathrm{CH}$ to the documented time of discharge.

\section{RESULTS}

The demographics of the 834 children are summarized in Table 1. Five hundred and fifty-five (66\%) of these children were male, and all received $\mathrm{CH}$ sedation for the primary repair of facial lacerations in an emergency room. The mean subject age was 30 months (range, 4-106 months), and the mean weight was 13.3 $\mathrm{kg}$ (range, $5-28 \mathrm{~kg}$ ). With the exception of fever $\left(>37.5^{\circ} \mathrm{C}, 13\right.$ children), there were no significant comorbidities. The mean $\mathrm{CH}$ doses in the six groups (in an ascending order) were 48, 55, $66,76,85$, and $97 \mathrm{mg} / \mathrm{kg}$, respectively.

The results of statistical analyses of sedation success and augmentation dose are shown in Table 2. No significant differences

\section{Table 1. Demographics of the six study groups}

\begin{tabular}{|c|c|c|c|c|c|c|}
\hline Group & $\begin{array}{l}\text { Chloral hydrate } \\
(\mathrm{mg} / \mathrm{kg})\end{array}$ & No. of patients & $\mathrm{M} / \mathrm{F}$ & Age (mo) & Weight (kg) & Comorbidity \\
\hline Group 1 & $48 \pm 2$ & 115 & $75 / 40$ & $28 \pm 13.9$ & $13.38 \pm 2.8$ & 1 \\
\hline Group 2 & $55 \pm 2$ & 116 & $80 / 36$ & $28 \pm 15.8$ & $13.02 \pm 3.3$ & 2 \\
\hline Group 3 & $66 \pm 3$ & 122 & $80 / 42$ & $29 \pm 14.4$ & $13.45 \pm 2.8$ & 1 \\
\hline Group 4 (standard) & $76 \pm 3$ & 202 & $136 / 66$ & $30 \pm 12.1$ & $13.49 \pm 1.9$ & 4 \\
\hline Group 5 & $85 \pm 3$ & 179 & $116 / 63$ & $32 \pm 15.0$ & $13.56 \pm 2.9$ & 5 \\
\hline Group 6 & $97 \pm 4$ & 100 & $66 / 34$ & $31 \pm 13.6$ & $13.10 \pm 1.9$ & 0 \\
\hline P-value & - & - & $0.98^{\mathrm{a})}$ & $0.12^{\mathrm{a})}$ & $0.48^{a)}$ & $0.19^{\mathrm{a})}$ \\
\hline
\end{tabular}


Table 2. Statistical analysis of sedation success and augmentation dose

\begin{tabular}{|lcccc|}
\hline Group & $\begin{array}{c}\text { Sedation } \\
\text { success (\%) }\end{array}$ & P-value & $\begin{array}{c}\text { Augmenta- } \\
\text { tion dose (\%) }\end{array}$ & P-value \\
\hline Group 1 & $113(98)$ & 1.000 & $21(18.2)$ & 1.000 \\
Group 2 & $114(98)$ & 1.000 & $20(17.2)$ & 0.879 \\
Group 3 & $121(99)$ & 0.415 & $23(18.8)$ & 1.000 \\
Group 4 (standard) & $197(97)$ & - & $37(18.3)$ & - \\
Group 5 & $177(98)$ & 1.000 & $27(15.0)$ & 0.413 \\
Group 6 & $99(100)$ & 0.667 & $11(11.0)$ & 0.131 \\
\hline
\end{tabular}

\section{Fig. 1. Proportion of children requiring augmentation dose}

In groups 5 and 6 , fewer children tended to need augmentation, but the difference was not statistically significant.

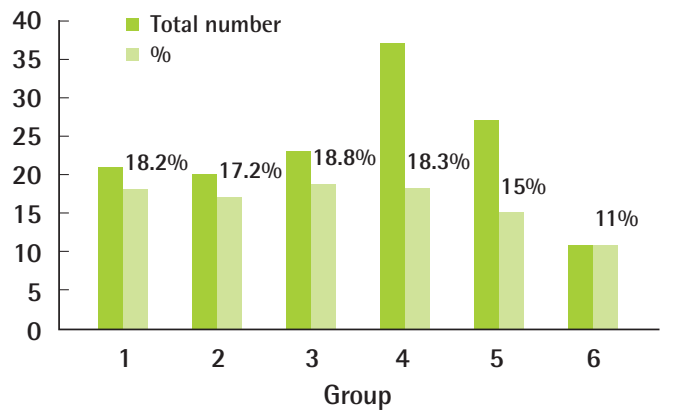

were found. However, in groups 5 and 6, fewer children tended to need augmentation without statistical significance. On the other hand, no increase in the need for augmentation was observed in groups 1 to 3 (Fig. 1).

A summary of the statistical analysis of the complication types is provided in Table 3. In the decreasing order of frequency, the complications encountered were vomiting, irritability, and desaturation. In group 1 , the overall frequency of complications was significantly lower than that in group 4 (the standard). However, no significant differences were observed among the other groups.

The results of our analyses of time variables are shown in Table 4. No significant intergroup difference was found between any two groups.

\section{DISCUSSION}

Our study shows that an initial $\mathrm{CH}$ dose of $48 \pm 2 \mathrm{mg} / \mathrm{kg}$ does not negatively affect the success rate of sedation or the need for additional sedative during the primary closure of facial lacerations in pediatric patients and that lower doses reduce the incidences of adverse effects and do not delay procedure readiness.

High efficacy, low complication rates, and the ease of administration support the widespread use of $\mathrm{CH}$. In previous stud-
Table 3. Analysis of types of complications

\begin{tabular}{|lrlc|}
\hline Group & $\begin{array}{c}\text { Complica- } \\
\text { tion (\%) }\end{array}$ & Type of complication & P-value \\
\hline Group 1 & $3(2.6)$ & Vomiting (3), irritability (1) & $0.021^{\text {a) }}$ \\
Group 2 & $6(5.1)$ & Vomiting (5), irritability (1) & 0.200 \\
Group 3 & $10(8.1)$ & Vomiting (10) & 0.841 \\
Group 4 (standard) & $19(9.4)$ & $\begin{array}{l}\text { Vomiting (18), irritability (2), } \\
\text { desaturation (1) }\end{array}$ & - \\
Group 5 & $14(7.8)$ & Vomiting (14) & 0.715 \\
Group 6 & $10(10)$ & Vomiting (9), irritability (1) & 0.838 \\
\hline a)Statistically significant results. & \\
\hline
\end{tabular}

Table 4. Statistical analyses of time variables

\begin{tabular}{|lcc|}
\hline Group & Time to procedure & Time of stay \\
\hline Group 1 & $52 \pm 31.3$ & $81 \pm 33.6$ \\
Group 2 & $53 \pm 28.1$ & $82 \pm 32.7$ \\
Group 3 & $53 \pm 30.8$ & $76 \pm 30.7$ \\
Group 4 (standard) & $59 \pm 33.7$ & $84 \pm 36.5$ \\
Group 5 & $57 \pm 30.5$ & $85 \pm 38.4$ \\
Group 6 & $57.4 \pm 30.0$ & $87 \pm 37.3$ \\
P-value & 0.302 & 0.220 \\
\hline
\end{tabular}

ies, various doses of $\mathrm{CH}$ between 50 and $100 \mathrm{mg} / \mathrm{kg}$ (up to a maximum of $2 \mathrm{~g}$ or $100 \mathrm{mg} / \mathrm{kg}$, whichever is the lowest) have been used, and efficacies of $<92 \%$ for the initial doses of 70,75 , and $100 \mathrm{mg} / \mathrm{kg}$ have been reported $[2,6,7,10,11]$. In the present study groups, efficacies ranged from $97 \%$ to $100 \%$, which is consistent with previous reports (Table 2). Sedation failure rates were reported to decrease from $15.5 \%$ to $5.5 \%$ in the case of $\mathrm{CH}$ augmentation [12]. Of the children included in the present study, $11 \%$ to $18.8 \%$ were given $\mathrm{CH}$ augmentation because of inadequate sedation by the initial $\mathrm{CH}$ dose; this decreased the sedation failure rate to $0 \%$ to $3 \%$ (Table 2 ).

$\mathrm{CH}$ sedation is associated with two types of adverse effects. First, adverse effects caused by irritation of mucous membranes, such as gastric distress, nausea, and vomiting, and second, adverse effects caused by $\mathrm{CH}$ overdose, which include ataxia, lethargy, deep coma, respiratory depression, hypotension, and cardiac arrhythmia [3]. In previously published studies, the rates of adverse effects were as follows: vomiting, $2 \%$ to $30 \%$; irritability, $1 \%$ to $6 \%$; and desaturation, $0 \%$ to $4 \%$ [13-17]. Similar frequencies were found in the present study, and most of the adverse effects were of the first type (Table 3). However, the lower dose group had a lower rate of adverse effects of the first type.

Overdose can be prevented by precisely measuring the $\mathrm{CH}$ syrup and the weight of the child. In the case of a child who has vomited, it is difficult to decide on the level of augmentation. In particular, when the initial dose administered is a dose that is close to the upper limit dose, augmentation is associated with a 
considerable risk of adverse effects. Thus, a lower initial dose of $\mathrm{CH}$ provides greater latitude when considering augmentation in a child who has vomited.

The possibility of re-sedation due to the long half-life of the active metabolite of $\mathrm{CH}$ has been well discussed in the existing literature. Cote et al. [18] and Malviya et al. [19] noted that only $48 \%$ of the children in their study returned to baseline activity and behavior within 8 hours and that $89 \%$ returned to baseline within 24 hours. Notably, $5 \%$ of all children did not return to baseline activity levels until the second day after the procedure. The adverse effects reported after discharge include motor imbalance $(31 \%)$, gastrointestinal effects (23\%), agitation (19\%), and restlessness (14\%) [18,19]. Accordingly, prolonged recovery and the high incidence of post-discharge adverse effects support the administration of as low a dose of $\mathrm{CH}$ as possible.

In an effort to reduce the possible adverse effects but retain efficacy, Bracken et al. [8] administered 20\% less $\mathrm{CH}$ than their standard dose $(75 \mathrm{mg} / \mathrm{kg})$ and found that this reduction had no negative effect on the outcome or the time to sedation. In the present study, the sedation success rate, time to sedation, and time of stay were almost identical for all the study groups, despite the significantly lower complication rate of group 1 (48 \pm 2 $\mathrm{mg} / \mathrm{kg}$ ).

The need for pre-sedational fasting to reduce the risk of aspiration has been losing ground. Keidan et al. [12] showed that fasting was associated with an increased failure rate of initial sedation and found that fasting increased the total dose of $\mathrm{CH}$ required and this in turn increased the sedation time. Further, unlike in elective diagnostic procedures such as MRI and EEG, an injured child visits a medical institution due to an accident and are likely not to have fasted in advance. Thus, in the present study, we did not require the children to fast prior to $\mathrm{CH}$ sedation $[12,20]$.

\section{REFERENCES}

1. Malis DJ, Burton DM. Safe pediatric outpatient sedation: the chloral hydrate debate revisited. Otolaryngol Head Neck Surg 1997; 116:53-7.

2. Mace SE, Brown LA, Francis L, et al. Clinical policy: critical issues in the sedation of pediatric patients in the emergency department. Ann Emerg Med 2008;51:378-99.e1-57.

3. World Health Organization. Chloral hydrate [Internet]. Geneva: World Health Organization; 2000 [cited 2013 Nov 22]. Available from: http://www.who.int/ipcs/publications/en/ cicad25.pdf.

4. Goodman LS, Gilman A. The pharmacological basis of therapeutics. 7th ed. New York: Macmillan USA; 1985.
5. Dalal PG, Murray D, Cox T, et al. Sedation and anesthesia protocols used for magnetic resonance imaging studies in infants: provider and pharmacologic considerations. Anesth Analg 2006;103:863-8.

6. Wheeler DS, Jensen RA, Poss WB. A randomized, blinded comparison of chloral hydrate and midazolam sedation in children undergoing echocardiography. Clin Pediatr (Phila) 2001;40:381-7.

7. Malviya S, Voepel-Lewis T, Tait AR, et al. Pentobarbital vs chloral hydrate for sedation of children undergoing MRI: efficacy and recovery characteristics. Paediatr Anaesth 2004; 14:589-95.

8. Bracken J, Heaslip I, Ryan S. Chloral hydrate sedation in radiology: retrospective audit of reduced dose. Pediatr Radiol 2012;42:349-54.

9. da Costa LR, da Costa PS, Lima AR. A randomized doubleblinded trial of chloral hydrate with or without hydroxyzine versus placebo for pediatric dental sedation. Braz Dent J 2007; 18:334-40.

10. Marti-Bonmati L, Ronchera-Oms CL, Casillas C, et al. Randomised double-blind clinical trial of intermediate- versus high-dose chloral hydrate for neuroimaging of children. Neuroradiology 1995;37:687-91.

11. D’Agostino J, Terndrup TE. Chloral hydrate versus midazolam for sedation of children for neuroimaging: a randomized clinical trial. Pediatr Emerg Care 2000;16:1-4.

12. Keidan I, Gozal D, Minuskin T, et al. The effect of fasting practice on sedation with chloral hydrate. Pediatr Emerg Care 2004;20:805-7.

13. Coskun S, Yuksel H, Onag A. Chloralhydrate in children undergoing echocardiography. Indian J Pediatr 2001;68:319-22.

14. Ronchera-Oms CL, Casillas C, Marti-Bonmati L, et al. Oral chloral hydrate provides effective and safe sedation in paediatric magnetic resonance imaging. J Clin Pharm Ther 1994;19:239-43.

15. Greenberg SB, Faerber EN, Aspinall CL, et al. High-dose chloral hydrate sedation for children undergoing MR imaging: safety and efficacy in relation to age. AJR Am J Roentgenol 1993;161:639-41.

16. Pereira JK, Burrows PE, Richards HM, et al. Comparison of sedation regimens for pediatric outpatient CT. Pediatr Radiol 1993;23:341-4.

17. Malviya S, Voepel-Lewis T, Eldevik OP, et al. Sedation and general anaesthesia in children undergoing MRI and CT: adverse events and outcomes. Br J Anaesth 2000;84:743-8.

18. Cote CJ, Notterman DA, Karl HW, et al. Adverse sedation events in pediatrics: a critical incident analysis of contributing factors. Pediatrics 2000; 105:805-14. 
19. Malviya S, Voepel-Lewis T, Prochaska G, et al. Prolonged recovery and delayed side effects of sedation for diagnostic imaging studies in children. Pediatrics 2000;105:E42.
20. Lipshitz M, Marino BL, Sanders ST. Chloral hydrate side effects in young children: causes and management. Heart Lung 1993;22:408-14. 